\title{
PEMBERDAYAAN KELOMPOK SEBAYA DAN KONSELING DI SMP WIDYA SAKTI UNTUK MENINGKATKAN GERAKAN SEHAT REPRODUKSI REMAJA
}

\author{
Sri Ratna Dewi ${ }^{1}$, Desak Putu Oki Lestari ${ }^{1}$, Ni Wayan Armerinayanti ${ }^{1}$, I Wayan Suwarna ${ }^{2}$ \\ ${ }^{1}$ Fakultas Kedokteran dan Ilmu Kesehatan Universitas Warmadewa \\ ${ }^{2}$ Rumah Sakit Prima Medika \\ Email: ratnasamuh@gmail.com
}

\begin{abstract}
Adolescent are a transition period and highly sensitive to the influence of new values. The problems they face are also quite complex, one of which concerns reproductive health. Some studies suggest that peers are the most dominant factor in influencing the adolescent reproductive health behaviors. This dedication activity aims to increase adolescent knowledge and activate the role of peers and counseling teachers in disseminating correct information about reproductive health. The method of implementing activities in the form of providing material on adolescent reproductive health by a talk from the expert, training and mentoring to peer groups in carrying out mini counseling, as well as training and counseling for counseling teachers. After the implementation of this program obtained increased peer group knowledge and counseling teachers on adolescent reproductive health respectively as much as $50 \%$ and $30.8 \%$. In addition, all peer groups are able to conduct mini-counseling as well as to do better counseling. Through this activity it is hoped that peer group partners and counseling is able to play an active role in continuously spreading information about adolescent reproductive health so that it can produce other peers who help keep the healthy atmosphere of the adolescents.
\end{abstract}

Keywords: adolescent reproductive health, peer groups, counseling groups

\section{Pendahuluan}

Sekolah Menengah Pertama (SMP) Widya Sakti merupakan sekolah swasta dengan akreditasi A yang terletak di Jalan Trenggana No. 8, Denpasar Timur, Bali (jarak sekitar 6,9 km dari Universitas Warmadewa). Sekolah ini terletak di Jalan Trenggana No. 8, Kelurahan Penatih, Kecamatan Denpasar Timur, dengan luas sekolah. Sekolah ini memiliki luas $1400 \mathrm{~m}^{2}$ yang terdiri dari 22 kelas (kelas pagi dan siang) dengan jumlah siswa sekitar 877 siswa dan guru sebanyak 66 orang. 
Lembaga Penelitian dan Pengabdian Kepada Masyarakat

Universitas Hindu Indonesia Denpasar

Volume 3, Nomor 1 Oktober 2019

ISSN: 2654-2935 (Online)

https://ejournal.unhi.ac.id/index.php/sewakabhakti

pp.1-9

Sekolah ini terletak di daerah perbatasan antara perkotaan dan pedesaan yang memungkinkan terjadinya akulturasi budaya heterogen yang menawarkan banyak pilihan gaya hidup. Mengingat masa remaja merupakan periode transisi dari masa kanak-kanak menuju dewasa. Pola karakteristik pesatnya tumbuh kembang ini menyebabkan remaja memiliki rasa keingintahuan yang besar, menyukai petualangan dan tantangan serta cenderung berani mengambil risiko tanpa pertimbangan yang matang (Soetjiningsih, 2004). Sementara SMP Widya Sakti ini hanya memiliki sedikit guru bimbingan konseling sehingga cenderung kurang mampu dalam memfasilitasi siswa dalam membimbing masalah yang dihadapi. Dari hasil wawancara dengan guru dan pegawai di SMP Widya Sakti, serta kuisioner yang disebarkan pada beberapa siswa didapatkan beberapa permasalahan terkait kesehatan (khususnya reproduksi remaja), antara lain:

a. Banyak kalangan yang masih mentabukan untuk membahas masalah kesehatan reproduksi remaja, sehingga permasalahan mengenai reproduksi remaja masih seperti fenomena "gunung es".

b. Banyaknya siswa SMP yang berpacaran. Hal ini dilihat dari kuisioner yang disebarkan kepada 53 anak, diperoleh sebanyak 25 anak $(47,17 \%)$ menjawab telah memiliki pacar. Bila tidak diimbangi dengan pengetahuan yang baik mengenai kesehatan reproduksi, maka dapat berisiko pada terjadinya pergaulan bebas.

c. Minimnya pengetahuan anak mengenai dampak pergaulan bebas, yaitu selain Kehamilan Tidak Diharapkan (KTD), juga berkaitan dengan peningkatan risiko terjadinya kanker serviks.

Kami mengangkat masalah kesehatan reproduksi remaja karena remaja saat ini mempunyai sifat yang permisif berkaitan dengan seksualitas sebelum menikah, sehingga menimbulkan berbagai masalah reproduksi dan seksualitas pada remaja (Duarsa, 2009). Data yang diberikan oleh Kisara (2008), menunjukkan bahwa sekitar 15 juta remaja usia 15-19 tahun melahirkan setiap tahunnya. Data Riskesdas (2010) menunjukkan bahwa proporsi penduduk usia 10 - 15 tahun yang pernah melakukan hubungan seksual pranikah di kalangan remaja 
Lembaga Penelitian dan Pengabdian Kepada Masyarakat

Universitas Hindu Indonesia Denpasar

Volume 3, Nomor 1 Oktober 2019

ISSN: 2654-2935 (Online)

https://ejournal.unhi.ac.id/index.php/sewakabhakti

pp.1-9

laki-laki adalah 17,7 persen, dan pada remaja perempuan 15,8 persen. Bahkan terdapat 0,5 persen perempuan dan 0,1 persen laki-laki yang sudah melakukan hubungan seksual pertama kali pada usia 8 tahun. Riskesdas (2010) juga menyebutkan bahwa 4,8 persen remaja usia 10-14 tahun dan 41,9 persen pada usia 15-19 tahun sudah menikah. Sementara dari hasil SDKI (2012) dijelaskan ada 12,8 persen remaja usia 15 - 19 tahun sudah menikah. Ini berarti, remaja melakukan hubungan seks dan mengalami kehamilan dalam usia yang sangat muda. Kehamilan remaja meningkatkan risiko kesehatan dan kematian pada ibu dan anak. Kasus aborsi di kalangan remaja juga sangat mengkhawatirkan. Dari 2,3 juta kasus aborsi per tahun di Indonesia, 30 persen dilakukan oleh remaja. Kehamilan di usia muda dan aborsi berpengaruh buruk terhadap kesehatan reproduksi remaja tersebut pada saat ini maupun nanti.

Selain berisiko menimbulkan KTD dan aborsi, seks pranikah di usia muda (di bawah 20 tahun) berkaitan dengan peningkatan insiden kanker serviks. Hal ini disebabkan oleh tingkat struktur anatomis jaringan serviks yang masih belum matang sebelum usia 20 tahun, sehingga rentan mengalami cedera yang memudahkan inokulasi Human Papillomavirus (HPV) yang merupakan salah satu agen penyebab kanker serviks. Adanya permasalahan terkait kesehatan reproduksi remaja di SMP Widya Sakti dan didukung oleh tingginya data mengenai masalah kesehatan reproduksi remaja menjadi latar belakang diangkatnya masalah ini sebagai bahan pengabdian masyarakat.

Adanya beberapa permasalahan tersebut mendorong kami untuk mengelompokkan mitra (SMP Widya Sakti) menjadi 2 kelompok sehingga memudahkan proses pendampingan, yaitu:

a. Kelompok 1 (kelompok mitra sebaya) yang berasal dari kelas 8 dan 9 yang masing-masing terdiri dari 5 orang

b. Kelompok 2 (kelompok mitra konseling) yang terdiri dari 2 orang guru Bimbingan Konseling (BK)

Tujuan dari program Pengabdian kepada Masyarakat (PkM) ini adalah untuk meningkatkan pengetahuan mitra sebaya mengenai kesehatan reproduksi 
Jurnal Sewaka Bhakti

Lembaga Penelitian dan Pengabdian Kepada Masyarakat

Universitas Hindu Indonesia Denpasar

Volume 3, Nomor 1 Oktober 2019

ISSN: 2654-2935 (Online)

https://ejournal.unhi.ac.id/index.php/sewakabhakti

pp.1-9

remaja dan melatih mereka melakukan "penyuluhan mini" agar dapat menyebarluaskan informasi (khususnya mengenai kesehatan reproduksi remaja) sehingga dapat membantu mengatasi masalah keterbatasan jumlah guru BK. Selain itu kegiatan PkM ini bertujuan untuk meningkatkan pengetahuan kelompok konseling di bidang kesehatan reproduksi remaja dan teknik konseling, serta melatih mereka untuk melakukan konseling.

\section{Metode Pelaksanaan}

Pelaksanaan PkM ini secara garis besarnya dibagi menjadi 3, yaitu persiapan, pelaksanaan, dan evaluasi. Pada tahap persiapan dilakukan koordinasi dan sosialisasi kegiatan meliputi pertemuan koordinasi dengan pihak Kepala Sekolah dan guru BK SMP Widya Sakti, Denpasar. Tahap pelaksanaan dilakukan dengan:

1. Memberikan pelatihan dan memediasi kegiatan belajar aktif bagi kelompok sebaya mengenai kesehatan reproduksi remaja sehingga memungkinkan adanya komunikasi 2 arah antara narasumber dan kelompok sebaya. Pelatihan akan diberikan dengan menggunakan media power point, brosur, dialog interaktif, dan video session.

2. Memberikan pelatihan kepada kelompok konseling mengenai kesehatan reproduksi remaja dan teknik konseling dengan menggunakan media power point, brosur, dan dialog interaktif.

3. Melakukan pendampingan terhadap kelompok sebaya dalam memberikan penyuluhan mini terkait kesehatan reproduksi remaja

4. Melakukan pendampingan terhadap kelompok konseling (guru BK) dalam memberikan konseling terkait kesehatan reproduksi remaja

Tahap evaluasi meliputi evaluasi kehadiran, pre dan post test, jumlah penyuluhan mini, dan jumlah konseling yang dilakukan oleh mitra.

\section{Hasil dan Pembahasan}


Lembaga Penelitian dan Pengabdian Kepada Masyarakat

Universitas Hindu Indonesia Denpasar

Volume 3, Nomor 1 Oktober 2019

ISSN: 2654-2935 (Online)

https://ejournal.unhi.ac.id/index.php/sewakabhakti

pp.1-9

Pengabdian masyarakat ini melibatkan guru BK sebagai mitra kelompok konseling dan kader siswa sebagai mitra kelompok sebaya, serta siswa. Kegiatan dilaksanakan dengan beberapa tahapan, yaitu diawali dengan mencari permasalahan yang dialami oleh mitra dan dilanjutkan dengan koordinasi dengan pihak sekolah mengenai teknis pelaksanaan PKM. Setelah itu dilanjutkan dengan pelaksanaan kegiatan inti dari PKM, yaitu pelatihan terhadap kelompok sebaya dan konseling sebagai mitra, serta diadakan pendampingan kepada mitra dalam melakukan penyuluhan mini dan konseling.

Pelatihan terhadap kelompok sebaya dilakukan dengan memberikan materi mengenai pengenalan alat reproduksi remaja, cara dalam merawat kebersihan alat reproduksi, masalah yang sering dijumpai oleh remaja, mulai dari cara membedakan keputihan yang normal dan abnormal, bahaya pergaulan bebas, pernikahan dini, penyakit menular seksual, HIV AIDS, kanker payudara, serta kanker serviks (gambar 1A). Selain itu kelompok sebaya juga diberikan informasi mengenai pentingnya vaksinasi kanker serviks. Setelah pemberian informasi tersebut, kelompok sebaya yang terdiri dari 10 siswa (memenuhi $100 \%$ target kehadiran) juga dilatih dan didampingi agar dapat memberikan penyuluhan mini sehingga informasi yang diperoleh dapat disebarluaskan ke teman-teman yang lain (gambar 1C). Kelompok sebaya juga dibekali dengan brosur untuk membantu mereka dalam memberikan penyuluhan mini.
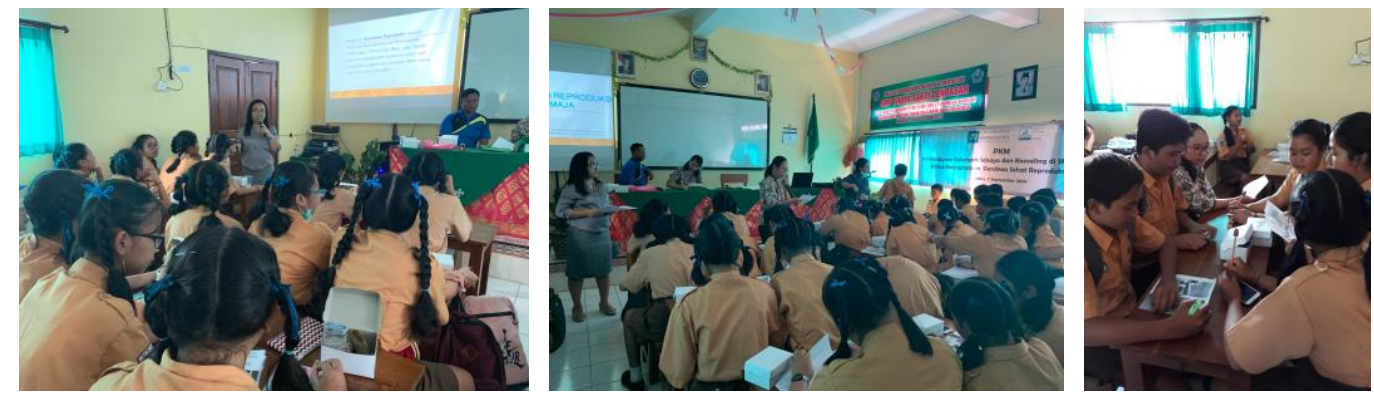

Gambar 1A. Penyampaian materi tentang kesehatan reproduksi remaja; B. Pelaksanaan post-test; C. Pendampingan saat penyuluhan mini

Melalui kegiatan ini diharapkan pengetahuan kelompok sebaya mengenai kesehatan reproduksi remaja menjadi meningkat. Hal tersebut dapat dilihat 
Lembaga Penelitian dan Pengabdian Kepada Masyarakat

Universitas Hindu Indonesia Denpasar

Volume 3, Nomor 1 Oktober 2019

ISSN: 2654-2935 (Online)

https://ejournal.unhi.ac.id/index.php/sewakabhakti

pp.1-9

melalui adanya peningkatan nilai rerata pre-test yang semula sebesar 5,5 menjadi 8,2 pada post-test, yaitu terdapat peningkatan sebesar 50\% (gambar 1B dan 2). Peningkatan pengetahuan dan adanya pelatihan dalam memberikan penyuluhan mini diharapkan dapat dimanfaatkan oleh kelompok sebaya untuk menyebarluaskan informasi ke teman-temannya, dan dapat memberikan saran yang positif bila ada teman yang meminta solusi atau pertimbangan mengenai masalah kesehatan reproduksi yang dihadapi. Karena ternyata menurut penelitian sebelumnya diperoleh data bahwa sebagian besar perempuan (62\%) dan laki-laki (51\%) mendiskusikan masalah kesehatan reproduksinya dengan teman (SDKI, 2017).

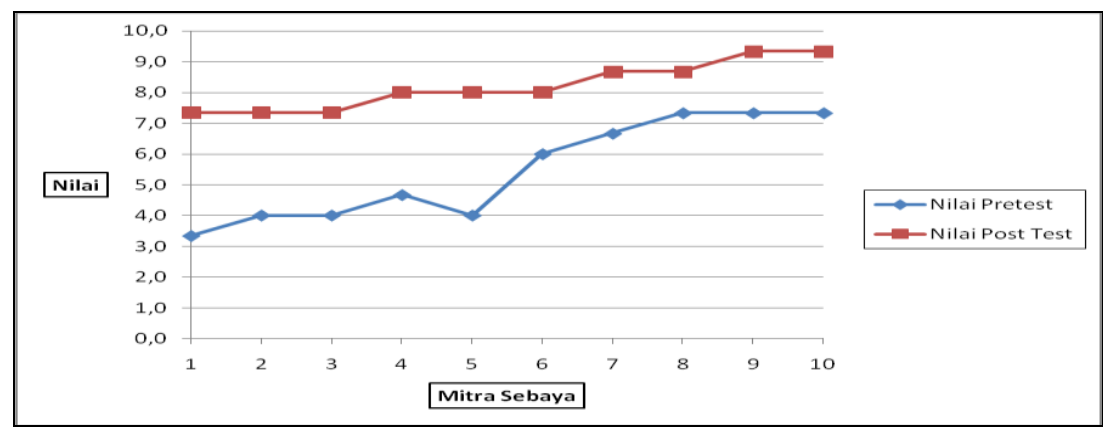

Gambar 2. Grafik nilai pre-test dan post-test mitra sebaya

Pada rangkaian kegiatan PKM ini mitra kelompok konseling (2 orang guru BK) juga diberikan pelatihan mengenai kesehatan reproduksi remaja dan pelatihan konseling (memenuhi 100\% target kehadiran). Pada kesempatan itu guru BK terlebih dahulu diberikan informasi mengenai kesehatan reproduksi remaja, kemudian dilatih untuk memberikan konseling dan dilakukan dialog interaktif untuk menggali permasalahan yang dihadapi dalam proses konseling (gambar 4A). Pada diskusi tersebut, narasumber juga membantu guru BK dalam mencari solusi terkait permasalahan yang dihadapi. Melalui pelatihan diperoleh peningkatan pengetahuan guru BK mengenai kesehatan reproduksi remaja dan teknik konseling yang dapat dilihat pada gambar 3, yaitu rerata pre-test mitra konseling sebesar 6,5 menjadi rerata post-test sebesar 8,5 (diperoleh peningkatan sebesar 30,8\%). 
Lembaga Penelitian dan Pengabdian Kepada Masyarakat Universitas Hindu Indonesia Denpasar

Volume 3, Nomor 1 Oktober 2019

ISSN: 2654-2935 (Online)

https://ejournal.unhi.ac.id/index.php/sewakabhakti

pp.1-9

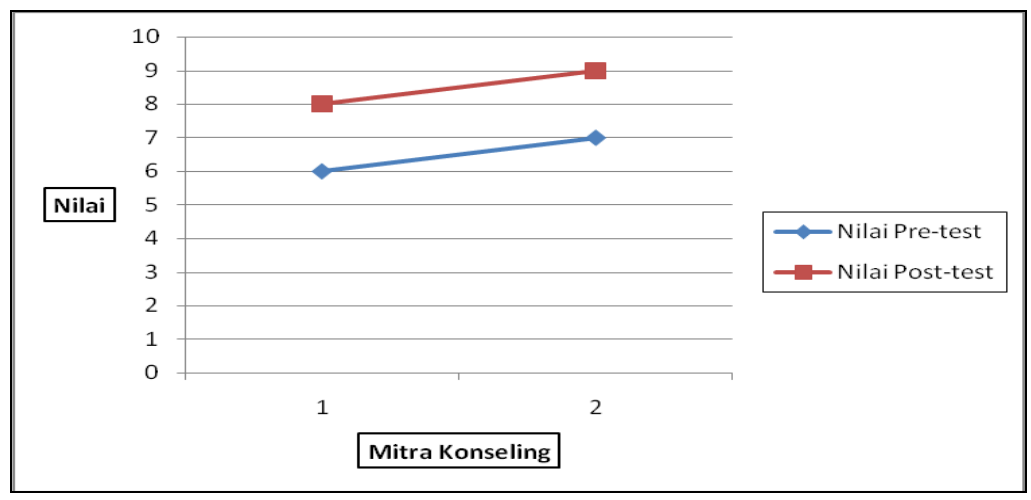

Gambar 3. Grafik nilai pre-test dan post-test mitra konseling
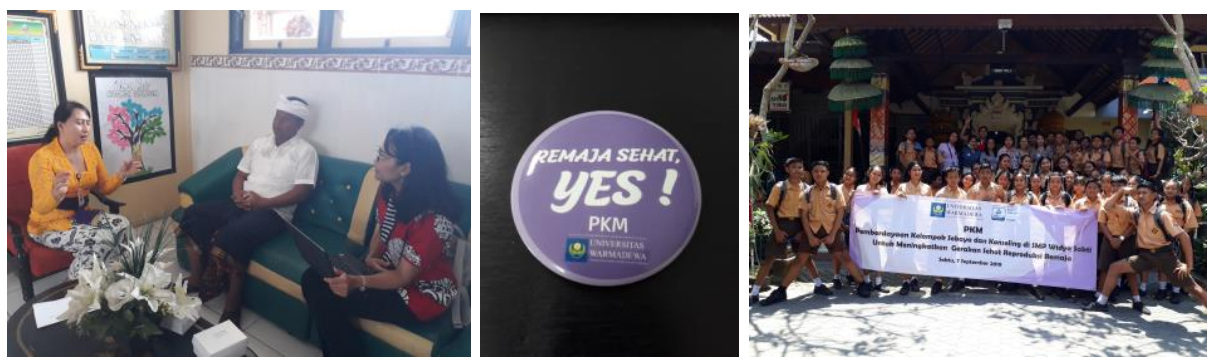

Gambar 4A. Pelatihan pada mitra kelompok konseling; B. Pin "remaja sehat"; C Foto bersama setelah kegiatan

Rangkaian acara pelatihan tersebut kemudian diakhiri dengan penyematan pin "remaja sehat" (gambar 4B) dan kemudian dilakukan foto bersama (gambar 4C). Setelah diadakan PKM mengenai kesehatan reproduksi remaja ini, mitra (baik kelompok sebaya maupun kelompok konseling) merasakan manfaat yang positif. Sepuluh orang mitra kelompok sebaya telah berhasil melakukan penyuluhan mini sebanyak satu kali. Bahkan kegiatan penyuluhan mini ini disambut baik oleh guru pembimbing ekstrakurikuler karena siswa menjadi lebih percaya diri dalam memberikan penyuluhan. Hal ini sangat membantu dalam mempersiapkan siswa dalam menghadapi lomba penyuluhan yang memang sering diikuti oleh SMP Widya Sakti. Mitra kelompok konseling juga merasakan manfaat yang baik setelah diadakannya PKM ini, mereka merasa baik dalam melakukan konseling dan bahkan siswa juga merasa nyaman untuk konseling dengan mereka.

\section{Penutup}


Jurnal Sewaka Bhakti

Lembaga Penelitian dan Pengabdian Kepada Masyarakat

Universitas Hindu Indonesia Denpasar

Volume 3, Nomor 1 Oktober 2019

ISSN: 2654-2935 (Online)

https://ejournal.unhi.ac.id/index.php/sewakabhakti

pp.1-9

\section{Simpulan}

Kegiatan pemberdayaan kelompok sebaya dan konseling di SMP Widya Sakti untuk meningkatkan gerakan sehat reproduksi remaja dapat berjalan dengan baik. Kegiatan ini berhasil meningkatkan pengetahuan kelompok sebaya dan konseling dalam bidang kesehatan reproduksi remaja, serta meningkatkan kemampuan guru BK dalam melakukan konseling. Hal tersebut dapat menunjang peran serta siswa sebaya dalam melakukan penyuluhan mini sehingga dapat membantu mengurangi masalah terkait kesehatan reproduksi remaja.

\section{Saran}

Kami berharap agar kegiatan ini dapat berlangsung berkesinambungan, sehingga kelompok sebaya menyebarkan informasi dan menghasilkan "sebayasebaya" lainnya yang dapat memberikan informasi yang benar mengenai kesehatan reproduksi remaja, serta kelompok konseling dapat menjalankan tugasnya dengan baik.

\section{Ucapan Terima Kasih}

Ucapan terimakasih disampaikan kepada Rektor, LPPM Universitas Warmadewa, dan keluarga besar SMP Widya Sakti yang telah memfasilitasi sehingga kegiatan ini berjalan dengan baik dan memenuhi target luaran.

\section{Daftar Pustaka}

Duarsa, D.P. 2009. Persepsi Remaja tentang Hubungan Seks Pranikah di Kota Denpasar: Perspektif Kajian Budaya. Disertasi. Denpasar: Universitas Udayana

Kisara. 2008. Bangkitkan Eksistensi Remaja demi Hak-hak Remaja. PKBi - Bali

Riset Kesehatan Dasar (Riskesdas). 2010. Badan Penelitian dan Pengembangan Kesehatan Kementerian Kesehatan Republik Indonesia.

Soetjiningsih. 2004. Tumbuh Kembang Remaja dan Permasalahannya. Jakarta: EGC. 
Jurnal Sewaka Bhakti

Lembaga Penelitian dan Pengabdian Kepada Masyarakat

Universitas Hindu Indonesia Denpasar

Volume 3, Nomor 1 Oktober 2019

ISSN: 2654-2935 (Online)

https://ejournal.unhi.ac.id/index.php/sewakabhakti

pp.1-9

Survei Demografi dan Kesehatan Indonesia (SDKI). 2012. Kesehatan Remaja.

Badan Pusat Statistik Badan Kependudukan dan Keluarga Berencana Nasional Kementerian Kesehatan.

Survei Demografi dan Kesehatan Indonesia (SDKI). 2017. Kesehatan Remaja.

Badan Pusat Statistik Badan Kependudukan dan Keluarga Berencana Nasional Kementerian Kesehatan. 